\title{
As famílias do afeto e seus reflexos na sociedade atual
}

\author{
The families of affection and their reflections in current society \\ Las familias del afecto y sus reflexiones sobre la sociedad actual
}

Recebido: 03/06/2021 | Revisado: 10/06/2021 | Aceito: 14/06/2021 | Publicado: 17/06/2021

\author{
Felipe Lima Diniz \\ ORCID: https://orcid.org/0000-0002-8434-258X \\ Universidade Federal Rural do Rio de Janeiro, Brasil \\ E-mail: felipelimadinizadv@gmail.com \\ Felipe Lima de Souza da Silva \\ ORCID: https://orcid.org/0000-0002-0758-776X \\ Universidade Federal Fluminense, Brasil \\ E-mail: felipelimauff@hotmail.com
}

\begin{abstract}
Resumo
Artigo Científico realizado a fim de estudar as diferentes formas de famílias, principalmente no que tange à busca pela felicidade e o consequente reconhecimento de famílias plurais e fora dos padrões arcaicos. De início, buscou-se caracterizar e definir o conceito de família e posteriormente demonstrar o quanto o poder estatal é importante e legitimador do conceito familiar. Para a elaboração deste estudo, foram analisadas todas as possibilidades de reconhecimento familiar e seus efeitos jurídicos. O presente artigo também analisou o princípio da afetividade e as diferentes formas de constituições familiares existentes. Buscou-se demonstrar que o afeto é o principal elo entre pessoas quando buscamos definir o que de fato é "família", demonstrando claramente que a afetividade não é um mero conceito vago, mas sim um princípio norteador. Isto posto, a temática central do presente trabalho é analisar a evolução do ente familiar vista sob uma ótica civil constitucional.
\end{abstract}

Palavras-chave: Família; Princípio da afetividade; Pluralidade.

\begin{abstract}
Scientific article carried out in order to study the different forms of families, especially with regard to the search for happiness and the consequent recognition of plural families and outside the archaic standards. Initially, we sought to characterize and define the concept of family and later demonstrate how important State power is and legitimizes the concept of family. For the preparation of this study, all possibilities of family recognition and its legal effects were analyzed. This article also analyzed the principle of affectivity and the different forms of existing family constitutions. We sought to demonstrate that affection is the main link between people when we seek to define what "family" actually is, clearly demonstrating that affection is not a mere vague concept, but a guiding principle. That said, the central theme of this work is to analyze the evolution of the family entity seen from a civil constitutional perspective.
\end{abstract}

Keywords: Family; Principle of affectivity; Plurality.

\section{Resumen}

Artículo científico realizado con el fin de estudiar las diferentes formas de familia, especialmente en lo que respecta a la búsqueda de la felicidad y el consiguiente reconocimiento de familias plurales y fuera de los estándares arcaicos. Inicialmente, buscamos caracterizar y definir el concepto de familia para luego demostrar cuán importante es el poder estatal y legitima el concepto de familia. Para la elaboración de este estudio se analizaron todas las posibilidades de reconocimiento familiar y sus efectos legales. Este artículo también analiza el principio de la afectividad y las diferentes formas de constitución familiar existente. Buscamos demostrar que el afecto es el vínculo principal entre las personas cuando buscamos definir qué es realmente la "familia", demostrando claramente que el afecto no es un mero concepto vago, sino un principio rector. Dicho esto, el tema central de este trabajo es analizar la evolución de la entidad familiar vista desde una perspectiva constitucional civil.

Palabras clave: Familia; Principio de la afectividad; Pluralidad.

\section{Introdução}

O presente artigo tem por objetivo analisar sob diferentes perspectivas o instituto da família eudemonista e socioafetiva.

Ademais, o trabalho demonstra ao leitor a importância do princípio da afetividade que, como será melhor explicado, é norteador para diferentes constituições familiares. 
Dessa forma, busca-se dar uma interpretação extensiva do Princípio da Afetividade, demonstrando que é possível uma constituição familiar diferente da dita família tradicional, analisando diferentes formas familiares sob uma perspectiva civil constitucional.

Ademais, também se busca mostrar que, o Princípio da Afetividade e a busca pela felicidade, são essenciais no Direito de Família e legitimam os vínculos filiais.

Em relação à conclusão deste trabalho, foi demonstrado de forma cristalina que, atualmente, temos presentes em nossa sociedade diversas formas de constituições familiares, reiterando que o afeto é o que une as "novas famílias", sendo que o Direito de Família não poderá receber tratamento matemático, devendo se moldar às realidades sociais.

\section{Metodologia}

\subsection{Tipo de estudo}

Trata-se de um estudo pautado na evolução do Direito de Família, especificamente no conceito do que é "família" e de que forma o Estado pode interferir nas relações familiares, seja direta ou indiretamente, por meio de suas três esferas de poder: Executivo, Judiciário e Legislativo.

Nesse sentido, para atingir o objetivo proposto, buscou-se trazer diferentes pensamentos dos principais doutrinadores do Direito de Família, além de conceitos históricos e dados objetivos retirados da legislação que rege nosso ordenamento jurídico vigente.

Dito isto, é importante ressaltar que todo o trabalho se deu através de pesquisas em obras jurídicas reconhecidas e respeitadas no âmbito acadêmico, além de se ter observado as jurisprudências dos Tribunais que, não por acaso, acabam pautando as grandes obras acadêmicas e até mesmo servindo de parâmetro para a propositura de leis infraconstitucionais.

\subsection{Procedimento de busca de dados}

A busca por publicações científicas, livros específicos, manuais jurídicos e decisões judiciais foi realizado no ano de 2020, utilizando-se na maior parte livros e manuais impressos, além de ter como base toda a legislação vigente.

Conforme se depreende da leitura da presente obra, a maior parte do trabalho tem por embasamento as decisões judiciais e as obras jurídicas, tendo em vista que os conceitos de "família" foram criados por intermédio de decisões judiciais e não a partir do Poder Legislativo.

\subsection{Análise de dados}

Optou-se por utilizar o gestor de referências bibliográficas, a saber: Metodologia da pesquisa científica (A. S. Pereira et al, 2018) como ferramenta para auxiliar na seleção dos estudos e na condução desta revisão.

Foram estabelecidos como critérios de inclusão: artigos científicos, editoriais de especialistas, e outras fontes (internet).

Deu-se preferência a materiais impressos e em sua predominância, a predileção foi por obras jurídicas que definissem de diferentes formas os conceitos de "família", além de trazer dados atualizados das decisões judiciais dos nossos tribunais superiores que, não por acaso, ocuparam o espaço do Poder Legislativo.

\section{As famílias do Afeto e os Reflexos na Sociedade Atual}

Durante muito tempo algumas posturas foram consideradas ilegítimas, entre elas podemos citar: o excesso de relações sexuais e passatempos amorosos, práticas sexuais depois dos 50 anos, direito ao orgasmo, opção pelo amor livre, práticas homossexuais, entre outras. 
Todavia, segundo Maria Berenice Dias em sua obra "Filhos do Afeto", tivemos mudanças de posturas na virada do século, entre elas podemos citar: a independência da mulher; a elevação dos filhos na ordem familiar; o direito ao divórcio; o controle de natalidade; a concepção humana assistida; a ampliação dos moldes parentais (filiação socioafetiva); a reciprocidade alimentar; a adoção por casais homossexuais; a homoafetividade como união estável; novos moldes familiares; mitigação da culpa na conjugalidade, entre outros. (Dias, 2016a)

Silvio de Salvo Venosa relata em sua obra a transição do campo para a indústria, e relata a influência da industrialização como ente transformador da composição familiar. (Venosa, 2017, p. 21)

Nesse mesmo sentido, podemos dizer que o divórcio originou a possibilidade de novas concepções familiares, e que o casamento nem sempre foi uma regra geral para constituição familiar. Para Silvio de Salvo Venosa: "As uniões sem casamento, apesar de serem muito comuns em muitas civilizações do passado, passam a ser regularmente aceitas pela sociedade e pela legislação.” (Venosa, 2017, p. 22).

Maria Berenice Dias, também leciona nesse sentido, ao ensinar que até o ano de 1977, todas as Constituições Federais consagravam a indissolubilidade do casamento, e explica que após esse período floresceu o amor romântico. Destarte, diz que: “[...] e, no momento em que o "sim" deixa de decorrer de uma manifestação da vontade alheia e passa a ser regida pelo sentimento, não há como jurar amor eterno". (Dias, 2016a, p. 27)

De certo, as novas uniões após o divórcio formaram simbioses de proles.

Sendo assim, a família dita informal deu espaço a outros conceitos de família, que são tratados por Maria Berenice Dias como um fenômeno da separação e dos casamentos contínuos que vieram a surgir. Dentre tantas nomenclaturas dadas às ditas famílias, temos alguns exemplos: “famílias recombinadas, recompostas, mosaico, recasadas, reconstituídas, misturadas, refeitas, reorganizadas, reestruturadas e com diversos outros nomes...” (Dias, 2016a, p. 31)

Por óbvio, não restam dúvidas de que a afetividade é o preceito fundamental na formação familiar, e a ideia de vínculos patrimoniais foi deixada para trás. Silvio de Salvo Venosa reafirma o conceito de família pautada em preceitos afetivos, e não mais em preceitos religiosos, patriarcais, patrimoniais e procracionais como eram presentes no século XIX. Vejamos:

"O afeto, com ou sem vínculos biológicos, deve ser sempre o prisma mais amplo da família, longe da velha asfixia do sistema patriarcal do passado, sempre em prol da dignidade humana. Sabido é que os sistemas legais do passado não tinham compromisso com o afeto e com a felicidade." (Venosa, 2017, p. 24)

Ademais, Rolf Madaleno tem o mesmo entendimento, pois em sua obra ensina que a família, outrora definida como patriarcal, não tinha o princípio da afetividade e a busca pela felicidade como seu principal núcleo, pois os interesses econômicos, o patrimônio e conceitos de certa forma "machistas", eram preponderantes naquela sociedade. (Madaleno, 2018, p. 45)

Paulo Nader ensina que pluralidade familiar não é inovação advinda deste século, e que na antiga organização grecoromana, a união entre o homem e a mulher já se fazia pelo casamento, e a família formava-se pelos descendentes de um mesmo ancestral. Assim, o filho adotivo, incorporava-se ao novo lar, sendo recebido como um de seus membros. (Nader, 2016, p. 46).

Indo mais além, para que não haja dúvidas sobre a formação familiar plural ser uma construção primitiva, segue trecho do livro: "A origem da família, da propriedade privada e do Estado" escrito por Frederich Engels e lançado em 1884, com tradução de Ruth M. Klaus em 2006, em que o autor afirma que os sistemas de parentesco e formas de família diferem dos de sua época no seguinte: cada filho tinha vários pais e mães. (Engels, 1884/2006, p. 31).

Em um momento mais atual, podemos dizer que a família, que outrora era institucionalizada por preceitos preconceituosos, deu espaço a possibilidades de novas formações, por sua vez pautadas no afeto. Nesse tom, Maria Berenice Dias nos traz ensinamentos do novo modelo de família afirmando que a nova família se estrutura nas relações de autenticidade, 
afeto, amor, diálogo e igualdade, e que ela não se confunde com o modelo tradicional, quase sempre cercado pela hipocrisia e pela falsidade institucionalizada. (Dias, 2016a, p. 29)

Desses ensinamentos, concluímos que os povos antigos tinham costumes diferentes da sociedade patriarcal do século XIX, assim constatando-se que a sociedade hodierna incorporou resquícios da organização greco-romana, ainda que a afetividade atualmente prevaleça sobre critérios econômicos, políticos, religiosos, sociais, de interesse do grupo familiar. (Calderón, 2017, p. 159)

\subsection{Desdobramentos históricos e natureza jurídica da família}

Para iniciarmos o estudo sobre o delineamento histórico do conceito de família, devemos nos atentar ao fato de que é necessário compreendê-la sob diferentes aspectos, com a finalidade de entendermos que a família eudemonista, pautada na realização pessoal de cada membro, é o modelo de família mais apropriado atualmente e que tem embasamento na dignidade humana.

Em tempo, devemos buscar conceitos e relações anteriores ao direito canônico para entendermos os motivos que levaram o nosso direito pátrio a legitimar com o Código Civil de 1916 a família matrimonializada, e a consequente distinção de filhos ditos legítimos e ilegítimos.

Paulo Lobo ensina sucintamente as passagens do patriarcado até a sua derrocada, em que há uma relação direta com a família matrimonializada, senão vejamos:

"A família patriarcal, que a legislação civil brasileira tomou como modelo, desde a Colônia, o Império e durante boa parte do século XX, entrou em crise, culminando com sua derrocada, no plano jurídico, pelos valores introduzidos na Constituição de 1988.” (Lobo, 2018, p. 18)

De acordo com estudos de Frederich Engels, os indivíduos do grupo familiar primitivo tinham relações sexuais entre si, chamada endogamia. Dessa forma, a mater sempre era certa, porém, o pai era desconhecido. (Engels, 1884/2006)

Para reforçar esse fato de práticas sexuais e incestos entre membros do mesmo grupo familiar, Frederich Engels (Engels, 1884/2006) cita relatos de estudos de Morgan, onde há o exemplo do sistema americano de parentesco, especialmente no Havaí, em que se constata ser o mais primitivo e que existia o incesto e relações sexuais entre seus membros. Nesse modelo familiar, não há distinção entre filhos de irmãos e irmãs, pois são irmãos e irmãs entre si, sendo de certa forma, filhos comuns. (Engels, 1884/2006, p. 30)

Após esse período primitivo houve mudanças significativas, tendo em vista que na poligamia a mulher desempenhava o papel centralizador da família, sendo um período marcado pelo matriarcado, onde não se chegou a institucionalizar. (Engels, 1884/2006)

Assim sendo, o homem passou a buscar relações com mulheres de outras tribos, tendo a presença de uma inclinação contra o incesto, e nesse momento tivemos a presença da monogamia, podendo dizer ser um sentimento de exclusividade, fato que é explicado por Silvio de Salvo Venosa: "Os historiadores fixam nesse fenômeno a primeira manifestação contra o incesto no meio social (exogamia)". (Venosa, 2017, p. 19)

Em outro momento, o autor citado acima utiliza o exemplo da Babilônia que instituiu o casamento monogâmico, todavia, com uma legislação que autorizava esposas secundárias, tendo em vista que o casamento buscava a procriação. (Venosa, 2017, p. 19)

Outrora, o livro: "A origem da família, da propriedade privada e do Estado" escrito por Frederich Engels, mostra que a realidade primitiva não era tão distante do modelo atual: "O estudo da história primitiva revela-nos que o homem praticava a poligamia e a mulher a poliandria, e em que, por consequência, os filhos de uns e outros tinham que ser considerados comuns". (Engels, 1884/2006, p. 31) 
Para reforçar o entendimento, temos um trecho do artigo científico: "novas entidades familiares e seu reconhecimento pelo ordenamento jurídico brasileiro", que corrobora com o pensamento: "Como consequência do princípio da autoridade, para a determinação do parentesco importavam mais a submissão ao pater famílias do que os próprios laços sanguíneos, não sendo estes, pois, relevantes como fundamento da família romana" (Costa et al., 2018, p. 9) ${ }^{1}$

Em contraposição aos estudos de Frederich Engels e de outros estudiosos mais recentes, Caio Mario da Silva Pereira, em seu Livro: "Instituições do Direito Civil" faz uma ressalva importante dizendo que os estudiosos "oferecem dados inequivocamente valiosos, mas pecam, às vezes, pelas informações generalizadas, que afrontam os mais vivos impulsos da natureza humana.” (Pereira, 2017, p.52)

Reitera o referido autor no sentido de ser mais aceita a ideia de família monogâmica: "Mais racional seria aceitar como originária a ideia da família "monogâmica”, defendida por Ziegler, Starck, Darwin, Westermarck.” (Pereira, 2017, p. 52)

Em um momento posterior tivemos a família "sacralizada" sendo consagrada pela Igreja católica e solenizada pelo Código Civil de 1916, em que apenas os filhos dito legítimos que eram concebidos do casamento tinham o reconhecimento jurídico e social, tendo em vista a função de procriação da família. Segue trecho do artigo científico: "Novas entidades familiares e seu reconhecimento pelo ordenamento jurídico brasileiro" que nos mostra a realidade à época: "O grande interesse era a procriação, destacando a função reprodutiva da família, daí por que a imposição da relação ocorrer entre exclusivamente entre um par heterossexual e fértil, uma vez que era importante a transmissão do patrimônio do chefe da sociedade conjugal aos seus legítimos filhos."2 (Façanha e Façanha, 2019)

Maria Berenice Dias entende que o divórcio ceifou a ideia de família sacralizada, conforme trecho de seu Manual de Direito das Famílias: “A instituição do divórcio (EC 9177 e L 6.515177) acabou com a indissolubilidade do casamento, eliminando a ideia da família como instituição sacralizada.” (Dias, 2015, p. 29)

Em um momento mais atual, temos segundo os ensinamentos de Silvio de Salvo Venosa que, a legislação infraconstitucional delimita o direito de família, considerando apenas os critérios sanguíneos e os de parentesco. Ademais, diz Venosa que o Direito de Família está sempre em constante mutação. (Venosa, 2017)

De certo, temos a clara percepção de que o conceito de família na história está baseada em interesses de instituições como o Estado e a religião, e que no direito pátrio evoluímos de forma a atender aos anseios sociais, momento em que o Judiciário teve seu papel central nessa evolução por meio de seus julgados que serão melhor retratados em capítulo próprio.

Paulo Nader conceitua e ensina as transformações que o conceito de família sofreu no decorrer do século. Segue os seus ensinamentos importantes para o direito familiarista:

“Atualmente, a razão de ser da família não se limita "à propagação da espécie, à permanência da raça e à educação dos filhos", como preconizava Louis Josserand na metade do século passado. O que dá corpo à instituição, fundamentalmente, é a comunhão de interesses." (Nader, 2016, p. 54).

Sem prejuízo, Paulo Nader ainda cita o fato de o Código Civil de 2002 não responder aos problemas da contemporaneidade, e faz menção até mesmo à multiparentalidade que só é admitida em leis esparsas, assim vejamos: “Decisões esparsas admitem a multiparentalidade e as famílias simultâneas”. (Nader, 2016, p. 55).

No tocante à natureza jurídica da família, temos o seguinte entendimento de Paulo Nader: "Embora alguns juristas tenham atribuído à família a natureza de pessoa jurídica, tal entendimento não prevalece na esfera doutrinária”. (Nader, 2016, p. 72).

\footnotetext{
${ }^{1}$ Disponível em: https://www.conpedi.org.br/publicacoes/0ds65m46/wn2plsse/8AK6jMw1OK7y3Lq9.pdf> Acesso em: 04 fev, 2019

${ }^{2}$ Disponível em: https://www.conpedi.org.br/publicacoes/0ds65m46/wn2plsse/8AK6jMw1OK7y3Lq9.pdf> Acesso em: 04 fev, 2019
} 
Complementa o referido doutrinador que: "Na esteira da maioria dos autores, reconhecemos na família uma instituição, conforme a teoria de Maurice Hauriou" (Nader, 2016, p. 73).

Corroborando com o entendimento de Paulo Nader, entende Silvio de Salvo Venosa que: "Em nosso Direito e na tradição ocidental, a família não é considerada uma pessoa jurídica, pois lhe falta evidentemente aptidão e capacidade para usufruir direitos e contrair obrigações." (Venosa, 2017, p. 25).

Ademais, reitera o fato de ser a família uma instituição, todavia, deixa as seguintes ressalvas: “A doutrina majoritária, longe de ser homogênea, conceitua família como instituição. Embora essa conclusão seja repetida por muitos juristas, trata-se de conceito por demais vago e impreciso." (Venosa, 2017, p. 25).

Isto posto, não há como negar o fato de que o conceito de família que conhecemos hoje, é sem dúvida oriunda de uma evolução histórica e social que deixou de lado os critérios patrimoniais para adotar critérios afetivos, sendo por fim, a família reconhecida como uma instituição com proteção do Estado.

\subsection{Famílias socioafetivas: novos fenômenos sociais}

Diante de todos os delineamentos históricos retratados anteriormente, como a exposição das ditas famílias primitivas e da então família matrimonializada, chegamos ao raciocínio de que a religião e o Estado foram cruciais para definição do conceito de família, e mais ainda, podemos afirmar que a afetividade é o núcleo da família contemporânea.

Em meio às inúmeras transformações sociais no conceito de família, não há como negar que o afeto é um requisito importante na formação da família moderna (Calderón, 2017), porém, podemos dizer que diante de tantas formações familiares, como a união poliafetiva, homoafetiva e as famílias reconstituídas, houve uma junção entre a família primitiva sem a religião como fator predominante e o afeto como fator essencial para essas novas relações.

Caio Mario da Silva Pereira sintetiza de forma sucinta a concepção de família moderna, vejamos:

"Na sua evolução pós-romana, a família recebeu a contribuição do Direito germânico. Recolheu, sobretudo, a espiritualidade cristã, reduzindo-se o grupo familiar aos pais e filho, e assumiu cunho sacramental" e complementa: "E veio revestir no Direito moderno outras características. Substituiu-se, à organização autocrática uma orientação democrático-efetiva. O centro de sua constituição deslocou-se do princípio da autoridade para o da compreensão e do amor." (Pereira, 2017, p. 55)

De fato, são latentes alguns sinais de evolução no conceito de família, principalmente com o desaparecimento da organização patriarcal, no direito e nos costumes, acabando com a figura do pater romano. Em contrapartida houve uma redução das famílias devido aos fatores urbanos e independência da mulher. (Pereira, 2017)

Essas mudanças na composição familiar são retratadas por Paulo Lobo por intermédio de dados do IBGE, senão vejamos:

“Comparando-se com a década de 1980, o Censo Demográfico de 2000 apurou que: a) a média de membros por família caiu de 4,7 para 3,4; b) o padrão de casal com filhos (família nuclear), com os pais casados ou convivendo em união estável caiu de $60 \%$ para $55 \%$; c) em contrapartida, o percentual de entidades monoparentais compostas por mulheres e seus filhos ampliou de $22 \%$ para $26 \%$ (em 2008 já tinha avançado para 34,9\%, mais de um terço das famílias); d) os solitários (solteiros ou remanescentes de entidades familiares) subiram de 7,3\% para 8,6\%; e) o decréscimo da taxa de natalidade por mãe é notável, passando de 2,7 filhos para 2,3 filhos; enquanto na década de 1960 era de 6,3 filhos em média, em 2008 a média já tinha sido reduzida para 1,89 nascimentos/mulher, inferior ao nível de reposição da população $(2,1)$; ) os mais velhos estão vivendo mais, demandando atenção das famílias, com as mulheres chegando a viver em média 72,3 anos e os homens 64,6 anos; g) a população é mais feminina, havendo 96,6 homens para cada grupo de 100 mulheres." (Lobo, 2011, p. 23)

Para Silvio de Salvo Venosa, a diferenciação entre o modelo familiar patriarcal e o modelo eudemonista e atual está relacionada critérios como: número de pessoas, objetivos e a função materna e paterna. (Venosa, 2017). 
O referido autor faz uma relação da família atual com a educação de seus filhos, no sentido de que as responsabilidades dos pais foram transferidas em alguns aspectos para as instituições de ensino; sem prejuízo, cita os ofícios que não são mais transferidos de pai para filho e a religião que não é mais ministrada em casa. (Venosa, 2017).

Silvio de Salvo Venosa de certa forma reitera o entendimento da doutrina ao fazer um delineamento histórico da evolução da família na qual o patriarcalismo perdeu força, principalmente com a Revolução Industrial, vejamos:

“A passagem da economia agrária à economia industrial atingiu irremediavelmente a família. A industrialização transforma drasticamente a composição da família, restringindo o número de nascimentos nos países mais desenvolvidos. A família deixa de ser uma unidade de produção na qual todos trabalhavam sob a autoridade de um chefe. O homem vai para a fábrica e a mulher lança-se para o mercado de trabalho. No século XX, o papel da mulher transforma-se profundamente, com sensíveis efeitos no meio familiar.” (Venosa, 2017, p. 21)

De certo, a legislação veio afastar os resquícios patriarcais do século $\mathrm{XX}$, e de certa forma o cunho individualista e patrimonial que era presente no Código Civil de 1916 cedeu espaço ao divisor de águas no Direito de Família que foi a Constituição Federal de 1988. (Venosa, 2017)

Sendo assim, o Código Civil de 2002 abandonou os arraigados princípios da família patriarcal contidos no Código de 1916, como ensina Silvio de Salvo Venosa: "Não ousou, porém, o Código de 2002 abandonar arraigados princípios clássicos da família patriarcal, para compreender os novos fenômenos da família contemporânea". (Venosa, 2017, p. 23)

Em complemento, temos posições mais críticas quanto à resposta que o Código Civil deu aos anseios contemporâneos, tendo em vista que não abarcou todos os temas importantes que tiveram sua legitimidade por intermédio de decisões judiciais e leis esparsas, assim entende Paulo Nader, vejamos:

"Relativamente ao Direito de Família pátrio, é de se reconhecer que o Códex de 2002 não responde aos questionamentos da contemporaneidade, além de não oferecer um sistema indutor de convergência doutrinária e jurisprudencial. Há tentativa de modernização do Direito de Família com o projeto de lei, oriundo do Senado Federal (PLS 470/13), que pretende a criação de um instrumento legal independente, instituindo o Estatuto das Famílias. Decisões esparsas admitem a multiparentalidade e as famílias simultâneas.” (Nader, 2016, p. 55)

Nesse mesmo sentido de tentarmos definir a família contemporânea, não há como negar o protagonismo da mulher na evolução da família que hoje conhecemos.

Ademais, como bem ensina Paulo Nader, o pensamento filosófico da metade do século XX e as duas grandes guerras que abalaram o mundo foram de grande importância para o Direito de Família, uma vez que a mulher passou a ter mais independência, mesmo que de forma tímida. (Nader, 2016)

Não obstante, somente após a edição do Estatuto da Mulher Casada, em 1962, que eliminou a discriminação da mulher face ao cônjuge varão, foi que finalmente a Lei $\mathrm{n}^{\circ}$ 6.515, de 26.12.1977 revogou a indissolubilidade do vínculo matrimonial, o que mudou o aspecto patriarcal arraigado em nossa legislação. (Nader, 2016)

Sem prejuízo, além da independência da mulher e a autonomia dos entes familiares, ainda tivemos mudanças científicas importantes que afastaram de certa forma o cunho religioso que sempre foi determinante para a definição de família. Tais mudanças científicas são descritas por Paulo Nader:

"Alguns fatores científicos e tecnológicos, como o surgimento de práticas anticonceptivas e sua influência nos costumes, a descoberta do DNA (ácido desoxirribonucleico) e a fertilização in vitro, induziram outras mudanças substanciais em nosso ordenamento. Ocorre o fenômeno de dissociação entre o exercício da sexualidade e a reprodução da espécie." (Nader, 2016, p. 52)

Temos ainda o fenômeno da repersonalização contemporânea das relações de família que, segundo ensina Paulo Lobo, "retoma o itinerário da afirmação da pessoa humana como objetivo central do Direito.” (Lobo, 2011, p. 26) 
Em síntese, a repersonalização do Direito de Família foi uma construção lenta que se deu principalmente com a Constituição Federal de 1988, e posteriormente com o Código Civil de 2002. Ademais, é importante citar o fato de que a nossa legislação sempre teve o cunho patrimonialista, e isso se comprova em números, vejamos: "No Código Civil de 1916 , dos 290 artigos da parte destinada ao direito de família, 151 tratavam de relações patrimoniais e 139 de relações pessoais”. (Lobo, 2011, p. 24)

De certo, a repersonalização do direito de família está ligada ao Princípio da Afetividade que, por si só, faz com que o Direito sofra uma mutação para atender à realidade, sendo assim, podemos afirmar que a família atual não tem os interesses patrimoniais como seu principal protagonista, conforme ensina Paulo Lobo:

\begin{abstract}
“A excessiva preocupação com os interesses patrimoniais que marcou o direito de família tradicional não encontra eco na família atual, vincada por outros interesses de cunho pessoal ou humano, tipificados por um elemento aglutinador e nuclear distinto - a afetividade. Esse elemento nuclear define o suporte fático da família tutelada pela Constituição, conduzindo ao fenômeno que denominamos repersonalização." (Lobo, 2011, p. 25-26)
\end{abstract}

Rolf Madaleno também realça o conceito de repersonalização presente no direito civil atual quando diz que: “o Direito Civil transformou-se ao deixar de se preocupar com a atividade econômica do cidadão e passar a regulamentar sua atividade social, cuidando de verticalizar o desenvolvimento da personalidade da pessoa.” (Madaleno, 2018, p. 91)

Não há como negar o papel da C.F/88 na repersonalização do Direito de Família, principalmente quando falamos de famílias monoparentais e da união estável, e até mesmo da união de casais do mesmo sexo, que acabou com o conceito de família procracional. Assim entende Maria Berenice Dias: “Em face da nova tábua de valores da Constituição Federal, ocorreu a universalização e a humanização do direito das famílias, que provocou um câmbio de paradigmas.” (Dias, 2015, p. 33)

Como já salientado, o critério afetivo se tornou protagonista na concepção de família moderna, prevalecendo sobre critérios econômicos, religiosos e político. Conforme entendimento de Ricardo Calderón: “O critério afetivo que figurava como coadjuvante no período da família clássica foi alçado à protagonista na família contemporânea" (Calderón, 2017, p. $159)$;

Por fim, Ricardo Calderón descreve as principais distinções entre a família clássica e o modelo contemporâneo de família. Em um primeiro momento descreve a família clássica:

"Do final do século XIX à metade do século XX; "Grande família" (vários participantes, muitos filhos e agregados); Transpessoal (prevalecia a família sobre os interessados dos seus integrantes); Matrimonializada (só existia pelo casamento civil); Patriarcal (o homem era detentor do poder); Hierarquizada (o homem estava acima da mulher, que estava acima dos filhos); Patrimonializada (o patrimônio era a preocupação central); Subserviente à religião (forte influência da Igreja); Formal (só o registro estatal validava); Retratada no Cód. Civil de 1916 (família tradicional); Legitimidade é o centro da preocupação (mulher legítima, fillhos legítimos, relacionamento legítimo)”. (Calderón, 2017, p. 159)

Ademais, descreve a família contemporânea da seguinte forma:

"Do fím do século XX aos dias de hoje; "Família Nuclear" e possíveis variações (poucos filhos, poucos integrantes); Eudemonista - prioridade na realização das pessoas sobre os interesses da família; Menor número - maior proximidade (há uma integração mais efetiva entre os integrantes); Maior subjetividade - esfera mais respeitada (pessoas são o centro); Famílias não fundadas no casamento (admite outras entidades familiares, ex: união estável, família monoparental etc.); Tendência à isonomia (entre homem e mulher, igualdade entre os filhos, igualdade entre casamento e união estável); Pouca pressão da religião e demais fatores externos (decrescem drasticamente de importância); Descrita nas entrelinhas da CF/88 (família democrática); Afetividade assume o protagonismo (filiação socioafetiva; homoafetividade e poliafetividade)". (Calderón, 2017, p. 160) 


\subsection{Família reconstituída, mosaico ou pluriparental}

A mudança de pensamento em relação ao conceito de família e o afeto como núcleo das relações familiares nos ajudam a entender o conceito de família reconstituída.

O conceito de família reconstituída se deve à quebra de rigidez de famílias pautadas somente no casamento, ou seja, as ditas famílias reconstituídas são oriundas de novas relações de pessoas que foram casadas ou viviam em união estável, e junto com sua prole passam a se relacionar formando novas entidades familiares. Rolf Madaleno ensina que:

"Seguindo sua trajetória de vida e, sobrevindo ou não o divórcio, ela se casa novamente ou estabelece uma união estável e passa a constituir uma nova família, que não tem identificação na codificação civil, e passa a ser chamada de família reconstituída, mosaica ou pluriparental.” (Madaleno, 2018, p. 50)

Nesse sentido, fica claro que as ditas famílias reconstituídas são pautadas em vínculos afetivos e não mais em vínculos matrimoniais e biológicos, devendo ter a proteção do Estado da mesma forma que outras conjunturas familiares. Esse é o entendimento de Silvio de Salvo Venosa: "Da mesma forma, a proteção do Estado deve ser dirigida às famílias reconstituídas, que com frequência abrangem filhos de duas estirpes, padrastos e madrastas, depois de uma nova união dos cônjuges." (Venosa, 2016, p. 24)

Como bem ensina Paulo Lobo em seu livro Direito de Família, "No caso da relação de enteados com padrastos ou madrastas emerge uma modalidade de parentesco por afinidade, tendo em vista o enunciado do art. 1.595 do Código Civil" (Lobo, 2011, p. 439).

Importante frisar que em relação às novas relações familiares não há deveres jurídicos específicos dos "padrastos" e "madrastas", mas pode-se cogitar o reconhecimento de multiparentalidade se estiverem presentes os requisitos da posse de estado de filiação.

Todavia, por mais que não tenhamos uma legislação que tutele deveres de cuidado para com os enteados, ensina Maria Berenice Dias em seu livro Filhos do Afeto que "o parentesco por afinidade que se instaura entre o padrasto ou a madrasta com seus enteados é inextinguível, a demonstrar que o direito de convivência entre eles há de se assegurar em harmonia com os mesmos direitos dos pais separados.” (Dias, 2016a, p. 54)

Rolf Madaleno cita o moderno Código Civil Argentino que tutelou o dever alimentar de padrasto e da madrasta com o enteado após ser desfeita a família reconstituída, lacuna existente em nossa legislação, o qual vejamos:

"Diferente e moderno se mostra, no entanto, o Código Civil argentino (Lei 26.994/2014), que entrou em vigência em $1^{\circ}$ de agosto de 2015, estabelecendo a obrigação alimentar do progenitor afim, cônjuge ou convivente (padrasto ou madrasta), em respeito ao filho do outro (CC argentino, art. 538 e arts. 672 a 676). Ordena o artigo 676 do Código Civil argentino, que a obrigação alimentar do cônjuge ou convivente em relação aos filhos do seu parceiro tem caráter subsidiário, e cessa este dever com a dissolução do vínculo conjugal ou a ruptura da convivência. Entretanto, se a mudança da situação ocasionar dano grave ao menor ou ao adolescente e o padrasto ou a madrasta assumiu durante a vida em comum o sustento do filho do outro, pode ser fixada uma cota alimentar de caráter assistencial e transitório, cuja duração será definida pelo juiz de acordo com as condições de fortuna do obrigado, as necessidades do alimentando e o tempo de convivência." (Madaleno, 2018, p. 52)

Em nosso ordenamento jurídico, há a possibilidade de inclusão de sobrenome de padrasto ou madrasta, na certidão de nascimento do enteado ou enteada, desde que haja relação afetiva, conforme ensina Paulo Lobo:

"Ampliando o reconhecimento jurídico da família recomposta, a Lei n. 11.924/ 2009 passou a admitir que o enteado ou a enteada, havendo motivo razoável, poderá requerer ao juiz de registros públicos que, no registro de nascimento, seja averbado o sobrenome de seu padrasto ou madrasta, desde que haja expressa concordância deste, que se acrescentará ao sobrenome existente.” (Lobo, 2011, p. 439) 
Para Maria Berenice Dias, deve-se assegurar ao padrasto ou à madrasta os mesmos direitos dos pais separados, com o compartilhamento do direito de convivência. Ademais, complementa dizendo que: "negar a relação paterno-filial entre pais e filhos afins é restringir o direito ao convívio familiar, é ignorar o direito à identidade, ambos de alçada constitucional". (Dias, 2016a, p. 54-55)

Dessa forma, percebe-se que não há que se afirmar ou cogitar, pelo menos em nossa legislação, a possibilidade de responsabilidades do padrasto ou madrasta para com seus enteados, porém, como bem observado por Maria Berenice Dias, se houver vínculo afetivo e posse de estado de filiação há a possibilidade de se ter um reconhecimento multiparental. (Dias, 2016b)

Sendo assim, a questão que se coloca na família reconstituída não é mais na relação apenas entre o casal, mas sim na responsabilidade para com a prole de ambos, pois o afeto se estenderá e chegará a um estágio que não poderá mais ser desfeito, o que poderá acarretar em posse de estado de filiação e consequentemente em reconhecimento multiparental.

\subsection{A família eudemonista:}

A família eudemonista nada mais é do que a família contemporânea, que tem como alicerce a afetividade e não mais os critérios patrimonialistas e consanguíneos antes arraigados em nosso direito.

Por óbvio, somente a partir da constitucionalização do Direito Civil e da dita repersonalização do direito foi que avançamos na desconstrução da sociedade patriarcal que subjugava os indivíduos que compunham o núcleo familiar.

Rolf Madaleno traz a definição que corrobora com o entendimento acima, pois a emancipação dos membros da família foi o avanço que aos poucos desfez o conceito de homem provedor e patriarca, antes contemplado em nosso direito. Vejamos: "O termo família eudemonista é usado para identificar aquele núcleo familiar que busca a felicidade individual e vive um processo de emancipação de seus membros" (Madaleno, 2018, p.69).

Nesse sentido, cabe destacar a presença dos Princípios da Dignidade humana e Solidariedade Familiar que alicerçam a família contemporânea, com ênfase na busca pela felicidade pessoal de cada membro e sua realização existencial na sociedade, o que acaba desaguando na afetividade como norteadora das relações familiares.

Maria Berenice Dias em seu manual de Direito das Famílias também entende que o amor e afeto são essenciais no conceito de família: “A família identifica-se pela comunhão de vida, de amor e de afeto no plano da igualdade, da liberdade, da solidariedade e da responsabilidade recíproca." (Dias, 2016b, p.222)

Por fim, Pablo Stolze Gagliano e Rodolfo Pamplona Filho, entendem que a família deve permitir a realização dos projetos pessoais de seus membros, na mesma linha de pensamento dos demais doutrinadores: “enquanto base da sociedade, a família, hoje, tem a função de permitir, em uma visão filosófica-eudemonista, a cada um de seus membros, a realização de seus projetos pessoais de vida." (Gagliano e Pamplona, 2017, p.79)

Em síntese, podemos constatar que a família eudemonista é a definição ideal para família contemporânea e repersonalizada, mas é cauteloso lembrar que ainda temos resistência por grande parte da sociedade em aceitar a pluralidade, que nada mais é que a realização pessoal.

\subsection{A família homoafetiva}

A família homoafetiva é uma realidade em nossa sociedade atual, mas devemos nos lembrar que nem sempre teve o respaldo jurídico necessário para deixar de ser informal e ausente de legitimação.

O fato de termos um modelo de pluralidade de entidades familiares, sem dúvida contribuiu e muito para a legitimação das uniões homoafetivas, assim entende Rolf Madaleno: 
“Ao menos desde o advento da Carta Política de 1988, a sociedade brasileira vivencia a identificação de uma nova forma de conjugalidade presente há muito tempo em outros países e agregada ao Direito brasileiro com o reconhecimento jurisprudencial da pluralidade de modelos familiares”. (Madaleno, 2018, p. 69)

Maria Berenice Dias busca o conceito de família e utiliza nossa legislação para ensinar que não há lei que impeça a união entre casais do mesmo sexo: "O Código Civil, quando trata do casamento, não exige que o casal seja formado por pessoas de sexo diferente." (Dias, 2016b, p.433).

Reitera Maria Berenice Dias no sentido de que a homossexualidade não é uma doença, um vício e nem um pecado, mas apenas uma forma de viver. Ademais, cita o fato de que na Classificação Internacional das Doenças - CID a palavra "homossexualismo" foi substituída por homossexualidade, tendo em vista que o sufixo "ismo" significa doença. (Dias, 2016b)

Mesmo diante de todos os avanços, é notório que o preconceito arraigado em nossa sociedade impediu o legislador de editar leis para legitimar as uniões entre casais do mesmo sexo, mas foi por intermédio das decisões judiciais que a família homoafetiva teve o reconhecimento devido. (Dias, 2016b)

Fazendo uma linha cronológica da jurisprudência, temos as seguintes conclusões: Inicialmente, a justiça deferia a um dos parceiros da união de pessoas do mesmo sexo indenização por prestação de serviços; posteriormente, passou a reconhecer as ditas uniões como sociedades de fato.

Como ensina Maria Berenice Dias, tivemos avanços significativos no Tribunal de Justiça do Rio Grande do Sul: “[...] ao definir, em 1999, a competência dos juizados especializados da família para apreciar as ações referentes à união das pessoas do mesmo sexo" (Dias, 2016b, p.439).

Complementa Maria Berenice Dias dizendo que: “[...] em 2001, pela vez primeira, reconheceu a união homoafetiva como entidade familiar, deferindo a herança ao parceiro sobrevivente". (Dias, 2016b, p.439).

Quanto ao posicionamento das cortes superiores, tivemos como marcos mais importantes os julgamentos da ADPF 132/2008 (Ação de Descumprimento de Preceito Fundamental) e da ADI 4.277/2009 (Ação Direta de Inconstitucionalidade), que tinham como pedido a validade das decisões administrativas que equiparavam as uniões homoafetivas às uniões estáveis, reconhecendo a união de casais do mesmo sexo como entidades familiares, tendo a decisão efeito vinculante, o que de certa forma trouxe garantias para esses casais, como bem observa Rolf Madaleno:

“[...] os alimentos, previstos no artigo 1.724 do Código Civil; a sucessão hereditária do artigo 1.790 do Código Civil; o direito à adoção pelos pares homoafetivos, cujo instituto vem regulado pelo Estatuto da Criança e do Adolescente, pois, como anota Viviane Girardi, companheiros podem adotar e a legislação não estabelece a necessidade da diversidade de sexos entre os adotantes; o exercício do poder familiar dos artigos 1.631 e 1.724 do Código Civil; o exercício da curatela, do artigo 1.775 do Código Civil; o uso do nome do companheiro, de acordo com o artigo 57, §§ $2^{\circ}$ a $6^{\circ}$ da Lei de Registros Públicos; a impenhorabilidade do bem de família que serve de residência ao casal, do artigo $1^{\circ}$, da Lei n. 8.009/1990; o direito à sub-rogação da locação de imóvel urbano quando a união estável se dissolve, oriunda do artigo 11 da Lei n. 8.245/1991; os direitos possessórios dos companheiros sobre os bens adquiridos conjuntamente durante a união, como a manutenção de posse, a ação de reintegração de posse (arts. 560 e ss. do CPC de 2015); os embargos de terceiro contra apreensão judicial (art. 674 do CPC de 2015); e, sobremodo, a conversão da união estável em casamento, prevista no artigo 1.726 do Código Civil, conquanto não evidenciados os impedimentos para o matrimônio, declinados no artigo 1.521 do Código Civil.” (Madaleno, 2018, p.71)

Isto posto, podemos ter a compreensão que fora necessário o Judiciário suprir a lacuna do Poder Legislativo, pois era preciso legitimar uma realidade que há muito tempo foi ignorada pela sociedade e seus conceitos religiosos e políticos que impediam pessoas do mesmo sexo de ter sua devida legitimidade perante o Direito, assim como adotar e matrimonializar a união, se assim achasse conveniente. Felizmente, a constitucionalização do direito legitimou o óbvio. 


\title{
3.6 A união poliafetiva
}

Inicialmente, é importante trazer conceitos das famílias primitivas para que possamos compreender a união entre três ou mais pessoas como uma união natural, e a monogamia como um princípio criado principalmente por fins religiosos e para favorecer o homem, como percebe-se em culturas orientais, onde o direito à prática da poliandria é restrita a muçulmanos ricos e poderosos (Engels, 1884/2006).

De acordo com os estudos de Morgan no livro escrito por Frederich Engels, tem-se o entendimento de que a monogamia surgiu de fato após transformações sociais, pois não há como negar a poligamia praticada pelo homem e a poliandria pela mulher, fato descrito na seguinte passagem do livro:

\begin{abstract}
"A concepção tradicional conhece apenas a monogamia, ao lado da poligamia de um homem e talvez da poliandria de uma mulher, silenciando como convém ao filisteu moralizante sobre o fato de que na prática aquelas barreiras sociais impostas pela sociedade oficial são tácita e inescrupulosamente transgredidas. O estudo da história primitiva revelanos, ao invés disso, um estado de coisas em que homens praticam a poligamia e suas mulheres a poliandria, e que por consequência, os filhos de uns e outros tinham que ser considerados comuns" (Engels, 1884/2006, p.39)
\end{abstract}

Quanto à monogamia, Frederich Engels relata as suas características predominantemente patriarcais e com fins religiosos, como vê-se a seguir:

\footnotetext{
"Nasce, conforme indicamos, da família sindiásmica, no período de transição entre a fase média e a fase superior da barbárie; seu triunfo definitivo é um dos sintomas da civilização nascente. Baseia-se no predomínio do homem; sua finalidade expressa é a de procriar filhos cuja paternidade seja indiscutível; e exige-se essa paternidade indiscutível porque os filhos, na qualidade de herdeiros diretos, entrarão, um dia, na posse dos bens de seu pai." (Engels, $1884 / 2006$, p.74)
}

Trazendo esses conceitos para o nosso Direito, devemos nos recordar do fato de que a Carta Constitucional de 1988 nos trouxe avanços significativos no conceito de família, mas sequer foi suficiente para abarcar todos os modelos familiares que poderiam vir a surgir.

Rolf Madaleno define a união poliafetiva da seguinte forma:

"Esta é a família poliafetiva, integrada por mais de duas pessoas que convivem em interação afetiva dispensada da exigência cultural de uma relação de exclusividade apenas entre um homem e uma mulher, ou somente entre duas pessoas do mesmo sexo, vivendo um para o outro, mas sim de mais pessoas vivendo todos sem as correntes de uma vida conjugal convencional." (Madaleno, 2018, p.66)

Nesse sentido, a família poliafetiva apenas externou a realidade de muitas pessoas, pois como bem observa Maria Berenice Dias, traição e infidelidade estão perdendo espaço. (Dias, 2016a)

Não podemos esquecer o fato de que o afeto é o liame que liga os entes familiares e por mais que tenhamos o princípio da monogamia como norteador em nosso Direito, não podemos negar que as relações entre mais de duas pessoas deve ter atenção jurídica, deixando de lado as ideologias religiosas que tanto perseguem nosso Direito. Corroborando com o entendimento, Maria Berenice Dias ensina que: "todas as formas de amar que fogem do modelo convencional da heteronormatividade e da singularidade, são alvo da danação religiosa e, via de consequência, da repulsa social e do silêncio do legislador." (Dias, 2016a, p.214)

Deve-se salientar o fato de que as famílias poliafetivas não são monogâmicas, pois há o elo do princípio da afetividade entre seus integrantes, além de ser uma relação aberta e pautada na livre iniciativa de seus membros em viverem como uma unidade familiar, ainda que incomum se comparada com outros modelos de família. 
Ricardo Calderón reitera o fato de não poder atribuir o princípio da monogamia às uniões poliafetivas, pois nas relações de poliafetividade temos um núcleo de conjugalidade único, e complementa o autor: "Esses relacionamentos superam a monogamia para conviver em uma relação múltipla, lastreada (segundo defendem) na lealdade e sinceridade entre os partícipes." (Calderón, 2017, P.343)

Assim também entende Rolf Madaleno: "Vivem todos em notória ponderação de princípios, cujo somatório se distancia da monogamia e busca a tutela de seu grupo familiar escorado no elo do afeto.” (Madaleno, 2018, p.66)

Há ainda quem entenda não ser a monogamia um princípio, mas uma característica do nosso sistema, tese defendida por Pablo Stolze Gagliano e Rodolfo Pamplona Filho em seu livro de Direito de Família, vejamos:

"Nessa linha, por coerência lógica, preferimos encarar a monogamia como uma nota característica do nosso sistema, e não como um princípio, porquanto, dada a forte carga normativa desse último conceito, é preferível evitá-lo, mormente em considerando as peculiaridades culturais de cada sociedade.” (Gagliano e Pamplona, 2017, p.131)

Por bem, cabe esclarecer que o reconhecimento da poliafetividade depende decisões judiciais e não apenas de escrituras públicas como ocorreu em Tupã - SP no ano de 2012 (Madaleno, 2018), já vedada pelo Conselho Nacional de Justiça no ano de 2018.

No mais, há muitas questões a serem debatidas com profundidade, entre elas estando a distinção entre família poliafetiva e família paralalela, que em muito diferem.

Maria Berenice Dias faz a seguinte distinção entre família simultânea e poliafetiva:

“A distinção entre família simultânea e poliafetiva é de natureza espacial. Na maioria das vezes, nos relacionamentos paralelos o homem - sempre ele! - mantém duas ou mais entidades familiares, com todas as características legais. Cada uma vivendo em uma residência. Já a união poliafetiva é quando forma-se uma única entidade familiar. Todos moram sob o mesmo teto. Tem-se um verdadeiro casamento, com uma única diferença: o número de integrantes. Isto significa que o tratamento jurídico à poliafetividade deve ser idêntico ao estabelecido às demais entidades familiares reconhecidas pelo Direito." (Dias, 2016b, p.214)

Ricardo Calderón também sustenta o fato de que há clara distinção entre as relações paralelas e as uniões poliafetivas, como vê-se em seus ensinamentos: "De forma sintética, resta possível afirmar que uniões paralelas são as que formam dois ou mais núcleos familiares conjugais distintos; uniões poliafetivas formam um único núcleo familiar conjugal, como mais de duas pessoas". (Calderón, 2017, p.344)

Por fim, chegamos ao entendimento de que a família poliafetiva não guarda consigo elementos que a liguem aos critérios primitivos de poligamia, pois há o vínculo afetivo e a lealdade entre os seus membros, sendo temerário sua negação pelo Poder Legislativo e Judiciário, devendo o Estado não intervir nas relações pessoais de modo a determinar o que é certo ou errado, e negar-lhes proteção.

\subsection{A família, os direitos fundamentais e a intervenção estatal}

Inicialmente, é essencial destacarmos que o Estado interfere nas relações familiares, mas a partir da constitucionalização do Direito Privado, as intervenções passaram a ser mínimas, como assim se espera de um Estado democrático, uma vez que o Direito deve servir ao indivíduo e as liberdades individuais dos componentes dos núcleos familiares devem ser respeitadas.

De certo, com a Carta Constitucional de 1988, o Direito de Família ganhou uma nova roupagem, passando a ganhar protagonismo o conceito de família eudemonista, na qual os indivíduos buscam a felicidade pessoal, não figurando mais o critério consanguíneo e patrimonial como determinantes. 
Cristiano Chaves de Farias e Nelson Rosenvald citam o fenômeno da desinstitucionalização da família para explicar as mudanças que caracterizam a dita família contemporânea. Vejamos: "Fenômeno da privatização da família ou desinstitucionalização da família, impondo uma intervenção mínima do Estado nas relações afetivas. (Farias e Rosenvald, 2016, p. 46)

Em meio a todas as transformações sociais e advindas com a constitucionalização do Direito Civil, não há como deixar de citar a importância dos princípios que regem todo o nosso ordenamento jurídico, em especial o Princípio da Dignidade da Pessoa Humana, referendado pelo nosso ordenamento jurídico.

A bem da verdade, o Princípio da Dignidade da Pessoa Humana é um legitimador do Estado Democrático de Direito, como ensina Caio Mario da Silva Pereira que: "De qualquer sorte, contemporaneamente, a afirmação e asseguramento dos direitos fundamentais, com ênfase na dignidade da pessoa humana, é condição de legitimação do Estado de Direito.” (Pereira, 2017, p.83)

Dessa forma, entendendo ser o Princípio da Dignidade da Pessoa Humana o norteador de todos os outros, e existindo o entendimento majoritário de que as interferências do Estado nas relações pessoais que agridam de alguma forma o respeito à liberdade e felicidade afrontam os princípios fundamentais, não cabe ao Estado ditar regras sociais, entendimento corroborado por Rolf Madaleno:

"E no Direito de Família é de substancial importância a efetividade dos princípios que difundem o respeito e a promoção da dignidade humana e da solidariedade, considerando que a família contemporânea é construída e valorizada pelo respeito à plena liberdade e felicidade de cada um de seus membros, não podendo ser concebida qualquer restrição ou vacilo a este espaço constitucional da realização do homem em sua relação sociofamiliar." (Madaleno, 2018, p.96)

Nesse sentido, não há legitimidade do Estado para interferir nas formações familiares e na realização pessoal de seus núcleos, pois os princípios fundamentais garantem aos indivíduos a busca pela felicidade de forma ampla, seja qual for a forma de união entre as pessoas. Assim entendem Cristiano Chaves de Farias e Nelson Rosenvald: “O Estado somente deve interferir nas entidades familiares para efetivar a promoção dos direitos e garantias (especialmente os fundamentais) dos seus componentes, assegurando a dignidade" (Farias e Rosenvald, 2016, p. 47)

A questão se torna ainda mais relevante se tomarmos como exemplo as novas formas de famílias que estão sendo formadas, como exemplo da poliafetividade. Ademais, devemos compreender que ao Estado cabe apenas a função de legitimar essas novas uniões. Assim também entende Anderson Schereiber em sua obra de Direitos da Personalidade: "direito à autodeterminação familiar, entendido como o direito de cada pessoa humana à formação de uma família, a ser reconhecida como tal pelo ordenamento jurídico.” (Schreiber, 2013, p.238)

Uma outra questão relevante a ser debatida é a aplicabilidade dos direitos fundamentais na vida dos componentes familiares e a discussão de ser o Direito de Família considerado público ou privado, face às intervenções do Estado na vida privada das pessoas.

Do ponto de vista principiológico, não pairam dúvidas que os direitos fundamentais devem ter incidência direta e imediata nas relações familiares, pois negar a sua aplicabilidade é negar o próprio direito.

A segunda questão debatida pela doutrina é o fato de ser o Direito de Família público ou privado, e não há dúvidas que é reconhecidamente direito privado, mesmo que haja intervenção estatal, o que não lhes retira a natureza de direito privado. Ademais, Paulo Lobo corrobora com esse entendimento: “o Direito de Família é genuinamente privado, pois os sujeitos de suas relações são entes privados, apesar da predominância das normas cogentes ou de ordem pública.” (Lobo, 2011, p.46) 
Entendimento idêntico é o de Pablo Stolze Gagliano e Rodolfo Pamplona Filho. Vejamos: "Com isso, podemos concluir que o Direito de Família, ramo do Direito Civil, integra, sob o ponto de vista enciclopédico, o Direito Privado, posto que reconheçamos a cogência da grande maioria de seus institutos, integrantes de seu corpo normativo positivo." (Gagliano e Pamplona, 2017, p.78)

Indo mais além, Cristiano Chaves de Farias e Nelson Rosenvald dizem ser o Direito de Família o mais privado de toda a seara cível: “Aliás, a família é o mais privado de todos os espaços do Direito Civil” (Farias e Rosenvald, 2016, p. 49)

Isto posto, resta claro que apesar de chegarmos as conclusões de ser o Direito de Família um direito privado, e ser voltado para atender aos fins mais nobres da natureza de cada membro familiar, ainda pairam dúvidas se os direitos fundamentais estão sendo respeitados e cumpridos, tendo em vista que o Judiciário cada vez mais cumpre o papel do legislador que ainda está arraigado por ideologias patriarcais e religiosas.

\section{Considerações Finais}

Do estudo realizado, foi demonstrado o conceito de família desde os primórdios da civilização até a contemporaneidade para buscar esclarecer ao leitor que a família se moldou de acordo com os interesses do Estado, sendo que, com a constitucionalização do Direito Civil, atualmente, não cabe mais por parte do Estado decidir o que é “família”, como outrora decidia, pautado em interesses religiosos.

$\mathrm{Na}$ sequência, foi exaustivamente ensinado o conceito e a importância da afetividade, que está presente nas famílias contemporâneas. Ademais, foi relatado didaticamente a linha cronológica que levou a sociedade e o direito pátrio a se desvincular de critérios patrimoniais, religiosos e patriarcais até adotar conceitos constitucionais de dignidade humana e a busca pela felicidade do indivíduo.

Destarte, o estudo realizado demonstrou a importância crucial dos princípios fundamentais adotados pela Carta Constitucional de 1988, que modificou a sociedade em que vivemos, principalmente o Direito de Família. Em sequência, foi mostrado que a constitucionalização e repersonalização do direito não permite mais a adoção de critérios patriarcais para definição de família, e muito menos a interferência do Estado, a não ser para garantir direitos fundamentais.

De certo, a partir da constitucionalização e repersonalização do Direito, a socioafetividade passou a ser aceita nos tribunais, e com isso podemos afirmar através dos estudos feitos que o critério biológico não é mais predominante, pois a afetividade se tornou um valor jurídico constantemente aceito pelo Judiciário.

Assim, restou comprovado que a família "tradicional" e a patriarcal perderam espaço para novas conjunturas familiares pautadas exclusivamente em critérios afetivos e plurais, predominando assim, a dita família eudemonista.

Por fim, a sugestão para trabalhos futuros é na linha de pesquisa do Direito de Família, com ênfase no princípio da afetividade, como exemplos: filiação socioafetiva, multiparentalidade e união poliafetiva. Ademais, há uma tendência social para a substituição de critérios sanguíneos e legais em prol de critérios socioafetivos, seara na qual trabalhos científicos só enriquecerão o debate jurídico.

\section{Referências}

Canezin, C. C. (2012). Filiação Socioafetiva: um Passo do Direito ao Encontro da Realidade. Revista Síntese de Direito de Família, 69.

Calderón, R. (2017). Princípio da afetividade no direito de família (2 ${ }^{\mathrm{a}}$. ed). Rio de Janeiro: Forense.

Dias, M. B. (2015). Manual de direito das famílias (10ª ed.). São Paulo: Revista dos Tribunais.

Dias, M. B. (2016a). Filhos do afeto. São Paulo: Revista dos Tribunais.

Dias, M. B. (2016b). Manual de direito das famílias (4ª ed.). São Paulo: Revista dos Tribunais. 
Research, Society and Development, v. 10, n. 7, e42410716757, 2021

(CC BY 4.0) | ISSN 2525-3409 | DOI: http://dx.doi.org/10.33448/rsd-v10i7.16757

Engels, F. (2006). A origem da família, da propriedade privada e do estado (R. M. Klaus, Trad., $3^{\text {a }}$. ed.). São Paulo: Centauro. (Obra original publicada em 1884).

Façanha, J. C. R. F. \& Façanha, I. F. Neto (2019). Novas entidades familiares e seu reconhecimento pelo ordenamento jurídico brasileiro. https://www.conpedi.org.br/publicacoes/0ds65m46/wn2plsse/8ak6jmw1ok7y3lq9.pdf.

Farias, C. C \& Rosenvald, N. (2016). Curso de direito civil: famílias (9ª ed). Salvador: JusPodivm.

Gagliano, P. S. \& Pamplona, R. Filho (2017). Novo curso de direito civil (7ª ed., Coleção Direito de Família). São Paulo: Saraiva.

Lobo, P. (2011). Direito civil: famílias (4a. ed., Coleção Direito Civil). São Paulo: Saraiva.

Lobo, P. (2019). Entidades familiares constitucionalizadas: para além do numerus clausulus. http://www.egov.ufsc.br/portal/sites/default/files/anexos//9407-1PB.pdf.

Madaleno, R. (2018). Direito de Família (8a . ed., rev., atual. e ampl.). Rio de Janeiro: Forense.

Nader, P. (2016). Direito de Família (Coleção Curso de Direito Civil). Rio de Janeiro: Forense.

Neves, R. S. (2012). Filiação, Afeto e o Padrasto: Como Tutelá-los. Revista Síntese de Direito de Família, (69).

Oliveira, C. A. (2010). Refletindo o afeto nas relações de família: pode o direito impor amor. Famílias no Direito Contemporâneo. Salvador: Juspodium.

Pereira, A. S.; Shitsuka, D. M.; Parreita, F. J. \& Shitsuka, R. (2018). Metodologia da Pesquisa Científica (1ª ed.). Santa Maria:UAB/NTE/UFSM.

Pereira, C. M. S. (2017). Instituições de direito civil (25a. ed.). Rio de Janeiro: Forense.

Pinto, I. M. (2008). Paternidade. Revista Brasileira de Direito de Família, (14).

Schreiber, A. (2013). Direitos da personalidade (2a. ed.). São Paulo: Atlas.

Tartuce, F. (2018). Direito de Família (12a . ed. rev., atual. e ampl., Coleção Direito Civil). Rio de Janeiro: Forense.

Valadares, M. G. M. (2010). Os meus, os seus e os nossos: as famílias mosaico e seus efeitos jurídicos. Leituras Complementares de Direito Civil. Salvador: JusPodivm.

Venosa, S. S. (2017). Direito civil: Família (17ª. ed, Coleção Direito Civil). São Paulo: Atlas. 